\title{
Distribution of bronchial gland measurements in a Jamaican population
}

\author{
J.A. H A Y E S ${ }^{1}$ \\ From the Pathology Department, University of the West Indies, Mona, Kingston 7, Jamaica
}

\begin{abstract}
Measurements of the gland thickness and Reid index have been made on bronchi obtained at necropsy on 53 male and 52 female Jamaicans. The mean values for the Reid index and mucous gland thickness obtained were 0.314 and $0.192 \mathrm{~mm}$. for males, and 0.302 and $0.170 \mathrm{~mm}$. for females respectively. No significant increase in value was seen with age, although the data suggest this trend. The results have been compared with data published from Montreal and the same overall Gaussian distribution is seen. This supports the suggestion that the gland measurements in non-bronchitic and bronchitic subjects do not fall into two distinct groups but are part of a continuous distribution. The similarity of the two studies is also of interest as the populations are drawn from two distinct environments, one from a non-industrialized tropical island, the other from a large city in the northern hemisphere.
\end{abstract}

Bronchial mucous gland enlargement is usually associated with the consistent production of mucoid sputum in chronic bronchitis (Reid, 1958). It was suggested that this mucosal change could be recognized by an increase in the ratio of mucous gland thickness to thickness of the bronchial wall (Reid, 1960), a ratio frequently called the Reid index. These measurements appear to be consistent within different parts of the bronchial tree, and measurements made in mainstem bronchi give a representative measure of the whole (Thurlbeck and Angus, 1967).

It is surprising that more use has not been made of these measurements in epidemiological studies, as it has been suggested that environmental factors, other than smoking, probably affect the development of chronic bronchitis (Thurlbeck and Angus, 1967). This supposition is supported by epidemiological data (Lawther, 1958; Reid, Anderson, Ferris, and Fletcher, 1964). A study in the west of England reported a distinct association between mucous gland size and smoking, but no firm conclusion was reached about the effect of urbanization (Field, Davey, Reid, and Roe, 1966). It was also observed that non-smokers showed evidence of mucous gland enlargement. A smaller study concluded that normal bronchial glands occur in an unpolluted environment (Hernandez, Anderson, and Foraker, 1964; Hernandez, Anderson, Holmes, Morrone, and Foraker, 1965).

1 Present address: Mallory Institute of Pathology, Boston City Hospital, Boston, Mass. 02118, U.S.A.
The existing evidence, therefore, indicates that atmospheric pollution is connected with enlargement of bronchial mucous glands.

Clinical chronic bronchitis is encountered in Jamaica, apparently in the absence of atmospheric pollution (Walshe and Hayes, 1967). It is therefore of interest to determine whether there is any evidence of mucous gland enlargement in a Jamaican population. This paper presents the results obtained in a prospective study of mucous gland size in bronchi obtained at post-mortem examinations on persons native to Jamaica, together with some comments on the findings.

\section{MATERIALS AND METHODS}

Post-mortem examinations were carried out on 105 Jamaicans of both sexes, aged 17 years and older, in the Pathology Department of the University Hospital of the West Indies. No selection of cases occurred apart from the exclusion of lower age groups. The cases were virtually consecutive. Transverse sections of the main bronchi immediately proximal to their bifurcation into lobar branches were taken, usually from the left lung, and were fixed in buffered $10 \%$ formalin for several days. Processed tissue was cut at $7 \mu$ thickness and the sections were stained routinely with haematoxylin and eosin and with periodic-acid-Schiff reagent. The sections were projected on to a vertical, flat surface and outlines of the bronchial glands, epithelial basement membrane, and the bronchial cartilage were traced on sheets of paper. A linear micrometer scale was projected on to the same sheet of paper imme- 
diately afterwards at the same magnification to allow inter-specimen comparison.

Lines were drawn on the tracings perpendicular to the basement membrane and inner surface of the bronchial cartilage. Measurements of the mucous gland thickness and of the wall thickness (basement membrane to internal surface of the cartilage deep to the fibrous perichondrium) were made along these radii and recorded. In the majority of cases a minimum of 10 readings were made from which a mean value was obtained. The mucous gland thickness, in millimetres, and the Reid index were calculated from these mean values.

The clinical record of each case was examined and pertinent data were recorded. In particular, a search was made for a definite history of smoking. Cigarette smokers were divided into three groups-light smokers, under 10 cigarettes daily; moderate? smokers, 10 to 20 cigarettes; and heavy smokers, $\frac{\bar{c}}{\bar{\omega}}$ over 20 cigarettes daily.

RESULTS

The mean values for the Reid index and mucous gland thickness are given for males in Table I, and for females in Table II. The cases in both sexes were grouped together and used to construct dis tribution curves for the Reid index (Fig. 1) and for mucous gland thickness (Fig. 2). The relationg of the Reid index and mucous gland thickness to the amount of cigarette smoking is shown iro Table III.

T A B L E I

REID INDEX AND BRONCHIAL GLAND THICKNESS IN MALES

\begin{tabular}{|c|c|c|c|c|c|c|c|c|c|c|c|}
\hline & & & \multicolumn{9}{|c|}{ Age Group } \\
\hline & & & $17-20$ & $21-30$ & $31-40$ & $41-50$ & $51-60$ & $61-70$ & $71-80$ & $81-90$ & Total \\
\hline $\begin{array}{l}\text { No. of cases } \\
\text { Mean Reid index } \\
\text { Mean gland thickness }\end{array}$ & $\begin{array}{l}\cdots \\
\cdots \\
\cdots\end{array}$ & $\begin{array}{l}\cdots \\
\cdots\end{array}$ & $\begin{array}{c}3 \\
0 \cdot 356 \\
0 \cdot 207\end{array}$ & $\begin{array}{c}8 \\
0 \cdot 289 \\
0 \cdot 164\end{array}$ & $\begin{array}{c}7 \\
0 \cdot 311 \\
0 \cdot 193\end{array}$ & $\begin{array}{c}7 \\
0 \cdot 264 \\
0 \cdot 178\end{array}$ & $\begin{array}{l}16 \\
0 \cdot 314 \\
0 \cdot 198\end{array}$ & $\begin{array}{c}10 \\
0 \cdot 336 \\
0 \cdot 190\end{array}$ & $\begin{array}{c}1 \\
0 \cdot 468 \\
0 \cdot 216\end{array}$ & $\begin{array}{c}1 \\
0 \cdot 390 \\
0 \cdot 139\end{array}$ & $\begin{array}{c}53 \\
0 \cdot 314 \\
0 \cdot 192\end{array}$ \\
\hline
\end{tabular}

T A B L E I I

REID INDEX AND BRONCHIAL GLAND THICKNESS IN FEMALES

\begin{tabular}{|c|c|c|c|c|c|c|c|c|c|c|c|}
\hline & & & \multicolumn{7}{|c|}{ Age Group } & \multirow[b]{2}{*}{$81-90$} & \\
\hline & & & $17-20$ & $21-30$ & $31-40$ & $41-50$ & $51-60$ & $61-70$ & $71-80$ & & Total \\
\hline $\begin{array}{l}\text { No. of cases } \\
\text { Mean Reid index } \\
\text { Mean gland thickness }\end{array}$ & $\begin{array}{l}\cdots \\
\cdots \\
\cdots\end{array}$ & $\begin{array}{l}\ddot{*} \\
\cdots\end{array}$ & $\begin{array}{c}3 \\
0 \cdot 225 \\
0 \cdot 119\end{array}$ & $\begin{array}{c}4 \\
0 \cdot 283 \\
0 \cdot 170\end{array}$ & $\begin{array}{c}9 \\
0 \cdot 262 \\
0 \cdot 138\end{array}$ & $\begin{array}{c}8 \\
0.355 \\
0 \cdot 234\end{array}$ & $\begin{array}{c}14 \\
0 \cdot 298 \\
0 \cdot 150\end{array}$ & $\begin{array}{c}8 \\
0.363 \\
0.229\end{array}$ & $\begin{array}{c}3 \\
0 \cdot 329 \\
0 \cdot 180\end{array}$ & $\begin{array}{c}3 \\
0 \cdot 211 \\
0 \cdot 087\end{array}$ & $\begin{array}{c}52 \\
0 \cdot 302= \\
0 \cdot 170=\end{array}$ \\
\hline
\end{tabular}



FIG. 1. Distribution curve for mean Reid index in 105 Jamaicans.

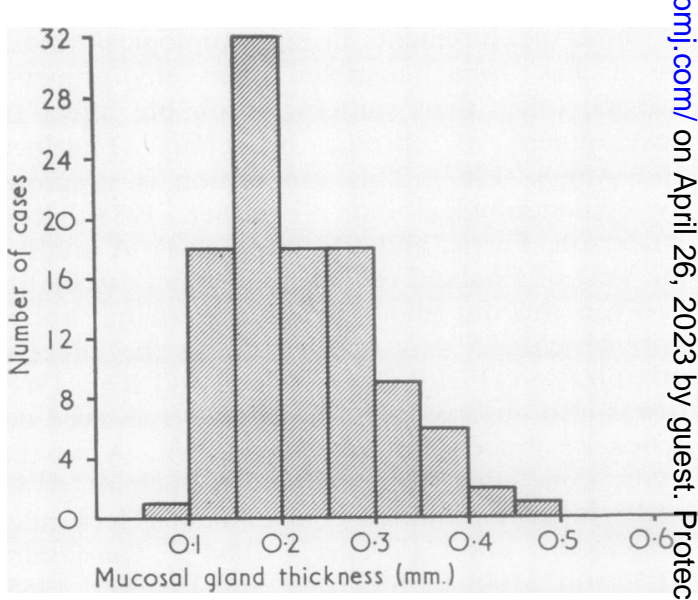

FIG. 2. Distribution curve for mean bronchial mucâts gland thickness in 105 Jamaicans. 
T A B L E I I I

SMOKING HABITS AND REID INDEX

\begin{tabular}{|c|c|c|c|c|}
\hline \multirow{2}{*}{\multicolumn{2}{|c|}{ Smoking Habits }} & \multirow{2}{*}{$\begin{array}{l}\text { No. of } \\
\text { Subjects }\end{array}$} & \multicolumn{2}{|c|}{ Reid Index } \\
\hline & & & Mean & Range \\
\hline $\begin{array}{ll}\text { Males: } & \\
\text { Non-smokers } \\
\text { Light } & \ldots \\
\text { Moderate } & \ldots \\
\text { Heavy } & \ldots \\
\end{array}$ & $\begin{array}{l}. \\
\cdots \\
. . \\
\end{array}$ & $\begin{array}{l}1 \\
4 \\
1 \\
5\end{array}$ & $\begin{array}{l}0 \cdot 399 \\
0 \cdot 331 \\
0 \cdot 392 \\
0 \cdot 325\end{array}$ & $\begin{array}{l}0.279-0.390 \\
0.208-0.449\end{array}$ \\
\hline $\begin{array}{l}\text { Females: } \\
\text { Non-smokers }\end{array}$ & .. & 9 & $0 \cdot 310$ & $0.237-0.412$ \\
\hline
\end{tabular}

\section{DISCUSSION}

The value of these observations depends on two premises: first, that increased sputum is associated with enlargement of the bronchial mucous glands and, secondly, that the sampling methods used are an accurate representation of the total gland mass. To my knowledge there has been no criticism of the first, so that it will be assumed to be correct. The methods used, however, have been criticized in various ways. It has been noted that commonly the glands do not lie between parallel lines formed by the bronchial basement membrane and the inner surface of the cartilage. Consequently, relative values for gland and bronchial wall thickness may not be accurate (Restrepo and Heard, 1963a). In addition, much of the gland mass may lie between, or external to, the cartilage plates, so that radial measurements underestimate the gland mass. It has also been reported that there is a significant variation between the area of glands at different sites in the bronchial tree (Restrepo and Heard, 1963a), particularly in cases with chronic bronchitis. This finding has been supported by Dunnill (1968), using a point count method, although he noted that the differences were minimal over a short length of bronchus. On the other hand, another study has shown that there is little significant difference between the Reid index measured at points throughout the major bronchi, including the main, lobar, and sublobar bronchi (Thurlbeck and Angus, 1967). It is not clear why this discrepancy exists between what appear to be similar forms of measurement. It may be, as suggested by Thurlbeck, that more distal bronchi tend to have fewer and more irregularly distributed glands, so that measurements should be restricted to the more constant gland pattern in major bronchi for comparative purposes. For simplicity in this study the measurements have been restricted to linear measurements used for the Reid index. Also, the mean of at least 10 readings on different radii has been taken in an attempt to minimize irregularity of gland distribution around the circumference of the bronchus. Although this simple measurement may not be the best yardstick of chronic bronchitis or of gland enlargement there is, as yet, no definite evidence to show that it is inferior to the measurement of gland area.

The figures obtained show that the Reid index tends to increase in value with advancing years, particularly in females, although in neither sex is the increase marked. The increase is less apparent for gland thickness. Because of the marked overlap of values between each age-group this study provides no support for the reported increase in gland size with age reported from England (Field et al., 1966), or from Florida (Hernandez et al., 1965), where persons over 40 years of age showed increased gland size even if they were nonsmokers. Unfortunately the number of cases with a definite history of smoking in this study is small (Table III), so that no conclusions can be safely drawn. However, the mean values obtained are not significantly different from those of the group as a whole, which could mean that smoking did not have much effect in the cases studied.

The curves for both Reid index and mucous gland thickness show a unimodal distribution pattern, the curve being broader and flatter for the Reid index (Fig. 1). If only chronic bronchitics had abnormal glands when compared with the remaining population then bimodal curves might be expected. Instead there is a normal distribution pattern in a population whose only basis of selection is that they were admitted to, and died in, a general hospital. This is similar to the finding reported from a study in Montreal (Thurlbeck and Angus, 1964).

The distribution curves obtained by the Montreal workers have been superimposed on the curves obtained in the present study (Figs 3 and 4). It can be seen that there is relatively little difference in the absolute values for mucous gland thickness in the two populations (Fig. 4). On the other hand, the curves for the Reid index show that the Montreal values are uniformly higher. This "bimodal" pattern in the Reid index, considered against the similarity of mucous gland thickness, suggests two possible explanations. First, there may be atrophy of the non-glandular tissues in the Montreal population, or, secondly, there is enlargement of the non-glandular portion of the wall in the Jamaican group. The former alternative is more attractive, particularly as atrophy of the bronchial wall has been demon- 




FIG. 3. Distribution curves for Reid index in Jamaican (hatched columns) and Montreal (open columns) cases.

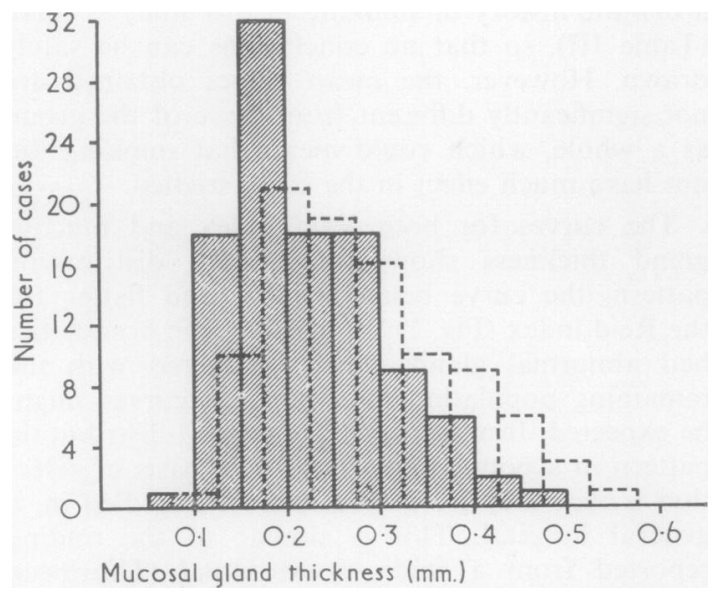

FIG. 4. Distribution curves for bronchial mucous gland thickness in Jamaican (solid line) and Montreal (interrupted line) cases. Data for the Montreal cases transposed from Thurlbeck and Angus (1964).

strated in emphysema (Wright, 1960), although other studies have not confirmed this (Restrepo and Heard, 1963b; 1964). However, the cases studied in Montreal were approximately 10 years older than the Jamaican cases, which may be significant. If both sets of observations are verified they would support the suggestion that the Reid? index is a more useful index of mucous gland $\frac{\bar{\sigma}}{\overline{5}}$ abnormality than is a simple estimation of the $\frac{\bar{\phi}}{\widehat{C}}$ gland area (Thurlbeck and Angus, 1964).

The data presented reveal little basic difference between the reported indices of bronchial gland $\vec{\circ}$ enlargement in one population living in a tem- perate, industrialized city and a second living in a $\vec{\omega}$ non-industrialized tropical island. If this implication is correct, it questions the importance of $\vec{x}$ industrial and urban pollution as a cause of the enlargement of bronchial glands. It also suggestscor a need for further studies of bronchial gland sizes in diverse environments.

I wish to thank Mr. E. Lewis for his technical assist- $\vec{c}$ ance and Professor G. Bras for providing facilities ato the Pathology Department, University of the West? Indies, Jamaica. The expenses for technical assistance and materials were covered by a grant from the Medical Research Council of Great Britain (G943/ $241 / T$ ), which is gratefully acknowledged.

\section{REFERENCES}

Dunnill, M. S. (1968). Morphometry of the human lung in health and disease. In Form and Function in the Human Lungs. Ed. Cumming? G., and Hunt, L. B., p. 19. Livingstone, Edinburgh.

Field, W. E. H., Davey, E. N., Reid, L., and Roe, F. J. C. (1966) ֶٌ๊ Bronchial mucus gland hypertrophy: its relation to symptomsD and environment. Brit. J. Dis. Chest, 60, 66 .

Hernandez, J. A., Anderson, A. E., Jr., and Foraker, A. G. (1964) $\overrightarrow{\vec{D}}$ Bronchial characteristics in pulmonary emphysema. Arch. Path.

The bronchial glands in aging,

Lawther, P. J. (1958). Climate, air pollution and chronic bronchitis? Proc. roy. Soc. Med., 51, 262.

Reid, D. D., Anderson, D. O., Ferris, B. G., and Fletcher, C. M. (1964). An Anglo-American comparison of the prevalence of bronchitis. Brit. med J., 2, 1487.

Reid, L. (1958). The pathology of chronic bronchitis. In Recent $\times$ Trends in Chronic Bronchitis. Ed. Oswald, N. C., p. 26. Lloyd Luke, London.

(1960). Measurement of the bronchial mucous gland layer: diagnostic yardstick in chronic bronchitis. Thorax, 15, 132 .

Restrepo, G., and Heard, B. E. (1963a). The size of the bronchia glands in chronic bronchitis. J. Path. Bact., 85, 305.

(1963b). Mucous gland enlargement in chronic bronchitis extent of enlargement in the tracheobronchial tree. Thorax, 18
334 . Amer. Rev. resp. Dis., 90, 395.

Thurlbeck, W. M., and Angus, G. E. (1964). A distribution curve foO chronic bronchitis. Thorax, 19, 436. (1967). The variation of Reid index measurements withio the major bronchial tree. Amer. Rev. resp. Dis., 95, 551 .

Walshe, M. M., and Hayes, J. A. (1967). Respiratory symptoms an\& smoking habits in Jamaica. Ibid., 96, 640 .

Wright, R. R. (1960). Bronchial atrophy and collapse in chronic obstructive pulmonary emphysema. Amer. J. Path., 37, 63. 